\title{
A Comparative Analysis of the Albanian and British English Vowel System
}

\author{
Lenida Lekli \\ PhD, "Aleksandër Xhuvani” University, English and German Language Department, Albania
}

\begin{abstract}
:
Analyzing the complexity of the articulatory process of the vowels in Albanian and English language is of crucial importance in distinguishing their unique phonetic and phonological properties. The standard Albanian vocalic system includes seven vowels, unlike the standard British English vowel system which consists of five vowels. Drawing points of similarity and differentiation between the vowel systems of the two languages requires detailed analysis regarding the degree of opening and the position of the tongue in the vowel tract. Therefore the purpose of this paper is to highlight differences and similarities of the vowel system (monophthongs) between standard Albanian language and British English. The seven Albanian vowels considerably differ from their five English counterparts, not only by their degree of opening but even by their placement concerning the horizontal movement of the tongue, which can be observed by examining the two vowel charts of both languages. The Albanian vowel system is displayed through a triangle, meanwhile the English vowel system is a schematic arrangement of vowels into a quadrilateral.Thus analyzing their properties by using a comparative approach regarding vowels articulation in both languages would help in generating a clear picture of their common and distinguishing characteristics.
\end{abstract}

Keywords: comparison, vowels, system, differences, similarities

\section{Introduction}

Human species converse, they ask questions, they give orders, they provide instructions, they sing songs, they show excitement, refusal through utterances etc., often without paying too much attention to the sounds and their various combinations that the speech mechanism articulates when fulfilling these speech activities during linguistic discourse in a variety of contexts. "Languages worldwide do come and go"( Ladefoged\& Disner, 2012, p. 2); Shakespearean English was not as sophisticated and elaborated as it is English language today. Buzuku and Bogdani's Albanian language went through fundamental transformations phonetically and phonologically until reaching today's contemporary version of the Albanian language. However, besides these linguistic modifications, there is one element that constitutes and provides the basics of speech of any language, that is sound.

The complexity of the articulation of speech sounds in any language is not an easy process. Its articulatory sophistication often provides difficulty in drawing conclusions concerning their physiological properties in the vocal tract. The articulation of sounds requires a coordination of muscles' movement during in-breathing and out-breathing of the air from the chest cage. As Roach says "all the sounds we speak are the result of muscle contracting. The muscles in the chest produce the necessary flow of the air that is needed for almost all speech sounds." (2009, p.8-9) Depending on this mass of air coming out from the lungs, and the vibration created between the vocal folds, there is generated a broad variety of vowel and consonantal sounds in English and Albanian language too, besides the alphabetical vowel and consonant letters the two languages possess.

The traditional classification of sounds is the one that groups them into two distinctive categories: vowels and consonants, a classification mainly based on the level of constriction created during airflow, may this airflow be lateral or central. This division of sounds is characteristic of all languages in the world not only English and Albanian language. "Vowels, which constitute the focus of this paper, are articulated in a manner different from that of consonants. The articulators, both active and passive are far apart to allow the airflow to exit unhindered, that is with open approximation. Given this fact, the manner of articulation classifications used for the consonants are inappropriate for the vowels. Moreover, vowels are produced in a smaller area of the vocal tract, mainly the palatal and velar regions, which means that the consonantal place specifications 
are also inappropriate." (Davenport, 2005, p.38) Furthermore, vowels differently from consonants are voiced sounds, with a strong vocal folds' vibration, excluding the classifying consonantal criterion of voicing.

As mentioned above, the primary focus of this contrastive research paper is the comparison of the English and Albanian vowel system, a comparative analysis which is going to be treated mainly in terms of three criteria:

- Iocalization (Memushaj, 2011, p.53) (horizontal position of the tongue in the vocal tract)

- degree of opening (tongue height or vertical position in the mouth cavity)

- $\quad$ lip rounding otherwise known as "lip posture" consisting of all the large number of postures this articulator can take during articulation. ( Ogden, 2009, p.59)

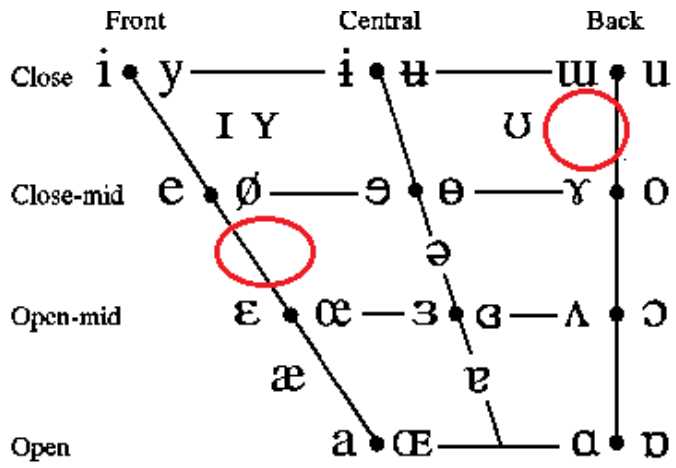

However, "part of the problem in describing vowels is that there are no distinct boundaries between one type of vowel and another in any kind of language. When talking about consonants, the categories are much more distinct. A consonantal sound may be a stop or a fricative, or a sequence of the two. But it cannot be half way between a stop and a fricative. Considered from this point of view, vowels are quite different. It is perfectly possible to make a vowel that is halfway between a high vowel and a mid vowel. (Ladefoged \& Johnson, 2011, p.87)

- $\quad$ Fig.1 Cardinal Vowels (Ogden, 2009, p.59)

In theory it is to be emphasized that it is possible to make a vowel at any specified distance between any two other vowels, as illustrated in the above chart through the small red circles." (Ladefoged \& Johnson, 2011, p.87)

The three articulatory criteria mentioned above will be analyzed and described in details in the following part of the paper pointing out characteristics of similarity and difference between the British English vowel system and the Albanian one.

\section{English and Albanian vowel system comparative analysis}

- Localization / Position of the tongue in the vocal tract

In terms of localization, it is to be emphasized that vowels in English and Albanian language depending on their articulatory position can be classified under the following headings: front, central and back. The reason why the English vowel chart (Fig.3) includes short and long English vowels is that the duration in English represents an important distinguishing element concerning the semantic aspect of words, meanwhile in Albanian language it is mainly a dialectic feature, rather than one which distinguishes words from one another.

In Albanian language unlike English one, there is a new nearly front vowel / y / (dyer , lyer etc.), which the English language does not recognize as such. 


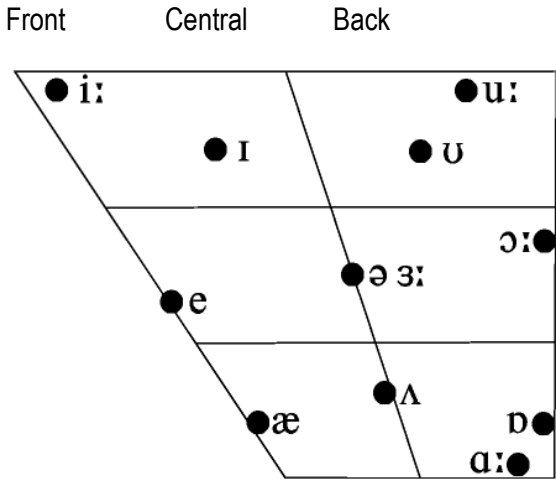

Fig.2 Albanian vowels (Beci, 2004, p.31)

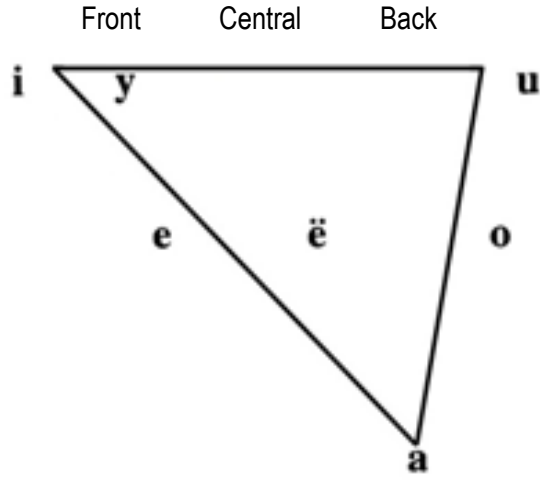

Fig 3. English short \& long vowels

(Davenport, 2005, p.38)

In English the / $\mathrm{y}$ / sound is either pronounced as a consonant mainly when encountered in an initial position, such as: Yard / ja: $\mathrm{d} /$, Young / $\mathrm{j} \wedge \mathrm{N} /$ etc. In other circumstances, when the sound is found in a medial position or final position ( by /bai/ ; hardly /'ha: dli / etc.) it bears the features of a front /i/ or diphthong /ai/.

Analyzing the rest of the sounds, it can easily be observed that the localization of the vowels in both languages differs considerably from one another. The English / $\mathrm{i}$ : / is closer to the Albanian one in terms of their articulatory positioning. Meanwhile the English short / / in comparison to the Albanian /i/ seems to be closer to the center than front.

The English front vowel /e/ ( let, bed, etc ) phonetically matches the articulation of the Albanian /e/ (det, mes,etc). A difference provides the English front vowel /æ/ which requires the Albanian learners of English language to try to articulate an opener version of their /e/ during which both sides of the tongue go down, accompanied by a broader opening of the jaws in order to guarantee a correct articulation of the vowel and correct pronunciation of words, such as cat /kæt/.

The two central English sounds $ә / 3$ positioned in the middle of the quadrilateral differ quite considerably from the Albanian lë/ placed in the middle of the triangle. The Albanian /ë/, may it be in a middle or final position in a word (such as: tavolinë, përmasë, etc. ) does not cause problems during articulation and pronunciation of the words. Meanwhile the two central English sounds ə/3:, due to their degree of duration often cause problems for the English foreign learners, not only during articulation but even in the pronunciation of the English words, for example: bird / b3:d/ , trainer / treinə/ etc. In such cases, the distribution of the vowels, whether they have a medial or final position can undoubtedly help during pronunciation.

Back vowels constitute another classification based on the positioning of the tongue. In both languages Albanian and English one, the articulation of the back vowels is accompanied by a back movement of the body of the tongue. However, it often depends on the distribution of these vowels within words, that is whether they might have an initial, medial or final position.

- Degree of opening (tongue height in the mouth cavity)

The degree of opening, otherwise known as the tongue height or vertical movement of the tongue in the mouth cavity provides another essential criterion when it comes to the classification of vowels in English and Albanian language too. Unlike, the previously mentioned classification of vowels according to the horizontal positioning of the tongue, the Albanian vowels seem to share more common characteristics with the English long vowels rather than the short English ones.

For instance, in the following group of words we can notice that for the pronunciation of the English word "duck" and the Albanian one "takim", the degree of opening during articulation for their common vowel is similar. Meanwhile in the word dark / da:k / the duration of the vowel requires a broader opening of the jaws, identifying a different vertical positioning of the vowel in the English quadrilateral. 
(English) Duck / d ^k /

(English) Dark / da: k /

(Albanian) Takim / takim /

If we go back to Fig. 3 and observe the position of the English short vowels in terms of their degree of opening it seems that they create a smaller quadrilateral inside the big one, corresponding with the appropriate vertical position of each vowel. Therefore the degree of opening in the articulation of vowels is different not only when comparing English and Albanian language, but even within one single language, taking as reference the short and long vowels of that language.

\section{- Lip rounding}

Lip rounding is otherwise recognized as the lip posture, the third basic criterion of the vowel description in English and Albanian language. Lips are considered to be active articulators, holding a number of postures. They can be spread, rounded, protruded, open, etc. (Ogden, 2009, p.59)

Both languages' vowels can easily be classified into rounded and unrounded vowels. In English the rounded vowels are / $\mathrm{u}, \mathrm{O}, \mathrm{Y}, \mathrm{J} / \mathrm{as}$ it can be observed in figure $\mathrm{nr}$. 4 . The rest of the vowels are unrounded. The rounding of the lips of these sounds can also be observed in the pronunciation of different words such as book, pull, drew, computer etc.

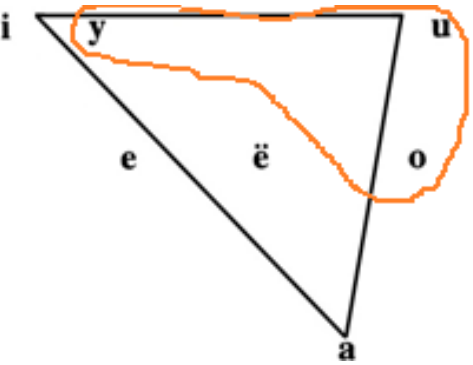

Fig.4 English rounded vowels

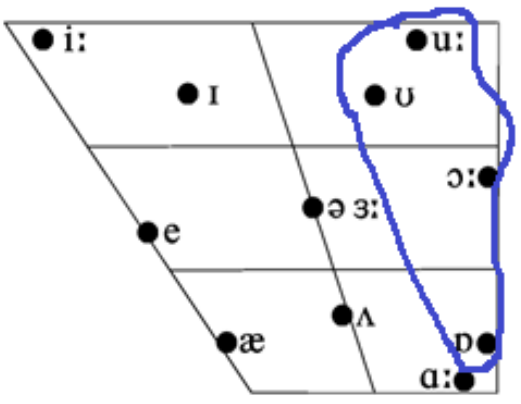

Fig. 5. Albanian rounded vowels

In Albanian language there are 3 rounded vowels y / o / u, meanwhile the four other ones are unrounded vowels. The lips' rounded posture of the vowels' pronunciation can also be observed in Albanian words such as druri , buka, kunadhe, dora, loja, tynel, byrek, etc.

What needs to be emphasized and pointed out as a common similarity between the two languages, English and Albanian one, concerning lip posture, it is to be said that the rounded vowels are found and easily articulated in a variety of words regardless of their distribution, whether they have an initial, medial or final position. 


\section{Conclusion}

Analyzing the vowels of the two languages, English and Albanian in terms of their articulatory features, is interesting and challenging at the meantime, considering the fact that the two languages differ considerably from one another.

English and Albanian language do not share the same spelling-pronunciation rule. English spelling does hardly match the pronunciation, with the exception of some one syllable words such as for / fJ: / , desk / desk /, task /ta: sk), etc. Meanwhile in Albanian language, the spelling and pronunciation perfectly match together, which means that words are pronounced in the same way as they are written.

The vowels of the two languages were mainly analyzed and compared regarding their physical features during their articulation in the vocal tract. Three criteria were taken into consideration when conducting the comparative analysis: the horizontal movement of the tongue, the vertical movement of the tongue, and lip rounding.

Referring to these comparisons it can be said that the English long and short vowels displayed in the quadrilateral do differ considerably from the Albanian vowels displayed in the triangle. Regarding the horizontal movement of the tongue, the English and Albanian vowels tend to share certain features, however, the Albanian vowels seem to reach the edges of the triangle more, unlike the English ones. According to the degree of opening or vertical movement of the tongue, English language offers more sound varieties, articulated in different positions differently form the Albanian language.

Finally, according to the criterion of lip rounding both languages seem to share common properties, despite their distribution in words or phrases, whether they might be found in an initial position, medial or final one.

\section{References}

[1] Beci, B. (2004). Fonetika e Gjuhës Shqipe. Tiranë: EDFA.

[2] Davenport, M. (1998). Introducing Phonetics and Phonology. UK: Oxford University Press.

[3] Ladefoged, P \& Keith Johnson. (2011). A Course in Phonetics. Canada: Cengage Learning International Offices.

[4] Ladefoged, P \& Sandra Disner.(2012). Vowels and Consonants. UK: Blackwell Publishing.

[5] Memushaj, R. (2011). Fonetika e Shqipes Standarde. Tiranë: TOENA.

[6] Odgen, R. (2009). An Introduction to English Phonetics. UK: Edinburgh University Press.

[7] Roach, P. (2009). English Phonetics and Phonology. A Practical Course. $4^{\text {th }}$ Edition. UK: Cambridge University Press. 